\title{
1 Ontogeny of daily activity and circadian rhythm in the Iberian lynx
}

2

3

4

5

6

7

8

9

10

\section{(Lynx pardinus)}

\section{.}

.

${ }^{1}$ Facultad de Ciencias Experimentales, Universidad de Huelva. Avda. Fuerzas Armadas s/n, (1)

${ }^{2}$ Facultad de Ciencias Experimentales, Universidad de Huelva. Avda. Fuerzas Armadas s/n, 21003 Huelva, Spain.
Xavier Manteca ${ }^{3}$

${ }^{3}$ Facultad de Veterinaria, Universidad Autónoma de Barcelona Bellaterra, 08193, , Barcelona, Spain.

(1)

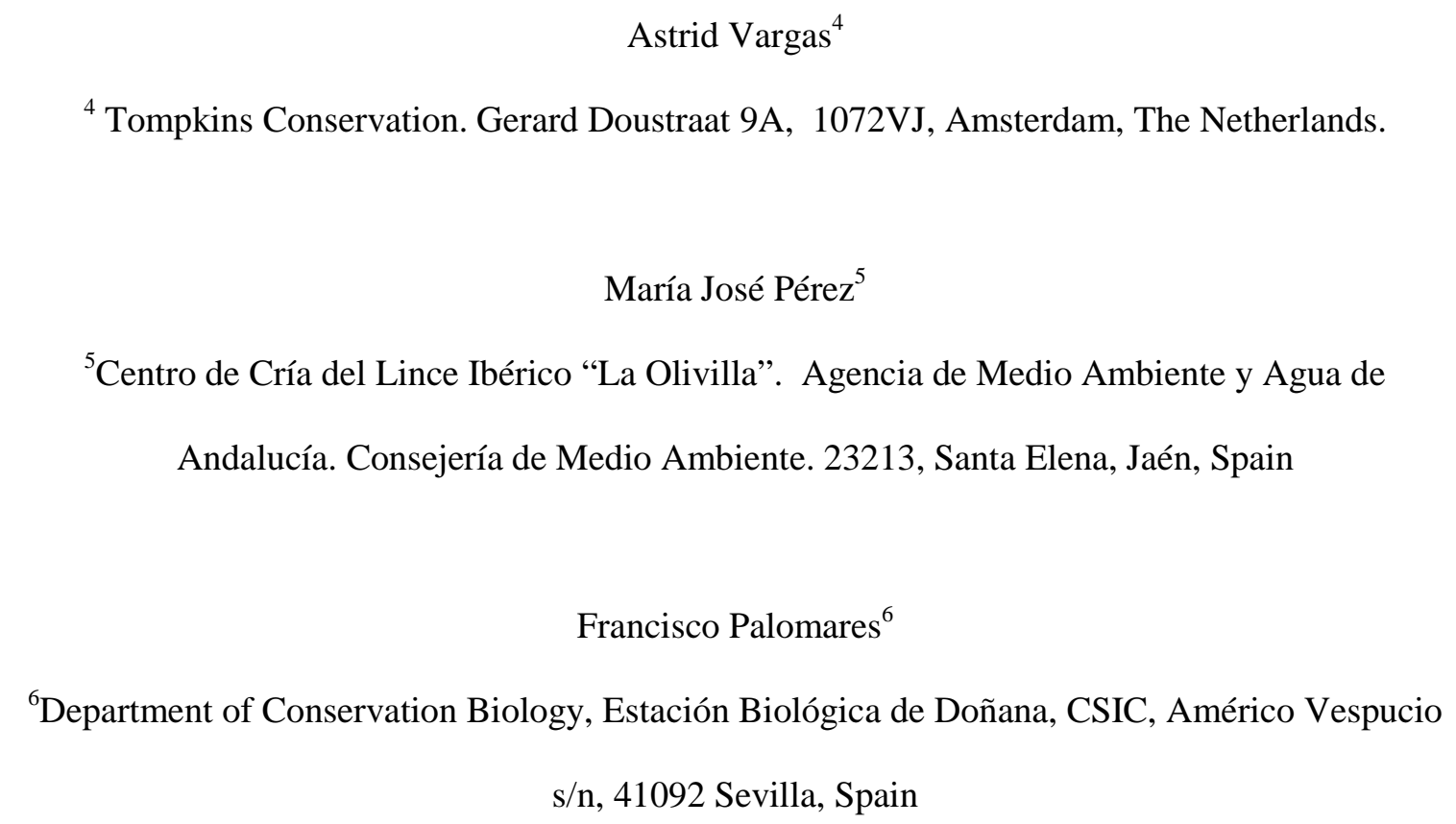




\section{Abstract}

The aim of this paper is to describe the ontogeny of the circadian activity rhythms in captiveborn Iberian lynx (Lynx pardinus) from birth to subadult age and to verify if they develop a bimodal circadian pattern similar to the one they show in the wild. The amount of daily activity and the circadian rhythmicity of 61 Iberian lynx (48 mother-raised and 13 hand-reared) cubs were studied in two breeding centers. During the first month of life, the cubs were active $30 \%$ of the day. Activity increased up to 50\% during the following two weeks, and then it remained constant until the end of the lynx physical development. The location of the breeding center affected the amount of daily activity of the cubs probably as result of different climatic conditions. Once the lynx cubs had completed their development, there was no difference in the time spent active between wild and captive lynx. Newborns had a constant level of activity throughout the day (24 hours) during the first month of life. During the second month, once they had developed sufficiently to leave the den, a crepuscular bimodal circadian rhythm started to emerge. This pattern was completely defined by the third month of life. The overlap in circadian activity was over 0.88 when comparing the sexes, breeding centers and rearing methods.

However, there was a significant difference between mother-raised and hand-reared cubs -the latter being more active in the morning-, as well as between breeding centers -again due to climate differences-. Finally, an overlap of 0.85 in circadian activity pattern was observed between wild and captive lynx, although the wild animals were more active at night.

55 Keywords: circadian rhythm, daily activity, Iberian lynx, ontogeny, reintroduction. 


\section{Introduction}

58 Circadian rhythmicity is present in various physiological mechanisms of animals. It affects sleeping and feeding patterns (Borbély and Neuhaus, 1978), as well as body temperature, brain activity and the production of hormones (Albrecht and Eichele, 2013). These rhythms have an endogenous time period, called free-running period, which lasts about 24 hours, but they can be modified by external environmental factors (Aton et al., 2004). Daylight is the main zeitgeber or synchronizer of circadian rhythmicity (Kavanau and Ramos, 1975). Within these rhythms, the circadian rhythm of activity is one of the main adaptations of species to their environment (Daan \& Aschoff, 1982). In predators, interspecific relationships between them and their prey play a fundamental role in the modeling of the activity rhythms (Halle, 2000; Lima, 2002), given that most predators must adapt their activity to that of their prey to improve their predatory efficiency (Monterroso et al., 2013). However, circadian activity rhythms can be modified by the combination of various environmental factors such as light (Pittendrigh, 1993) and temperature (Kolbe et al, 2007; Palkova et al, 1999).

Wild animals living in captivity often suffer disturbances in both their behavior and their activity rhythms (Berger, 2011). The captive environment may be very different to the wild one. The lack of space and natural stimuli, as well as captive husbandry practices, may hamper the development of the normal behavior of the species. A familiar example is provided by the artificially altered endogenous activity rhythms of carnivores as a result of the way they are fed, namely with dead meat (i.e. they cannot develop hunting behaviors) and on a fixed time schedule during the working hours of the keepers (Shepherdson et al. 1993). The difficulties in developing natural behaviors in captivity may lead to a reduction in animal welfare and to an increase in the prevalence of diseases (Munson et al., 2005) and stereotypical behaviors

80 (Carlstead, 1996; Shepherdson et al., 1993), such as pacing (Clubb and Vickery, 2006).

81 Preventing these negative effects is always important for ethical reasons, but even more so when

82 the goal of breeding animals in captivity is to reintroduce them into the wild. Animals that are

83 being breed for reintroduction programs should be housed in well-enriched and spacious 
enclosures and husbandry practices must strive to prevent the modification of circadian cycles of activity, as released animals must have their activity pattern synchronized with that of species in the wild. And in the case of predators that actively chase their prey, they have to be able to hunt, and particularly during the time of day that prey are active, i.e. available, in the wild (Eriksen et al., 2011).

The Iberian lynx, Lynx pardinus, is a wild felid species that is currently being breed for reintroduction in Spain and Portugal. The objective of the Iberian Lynx Captive Breeding Program (hereafter ILCBP) is to breed physically and behaviorally healthy lynx, which can reinforce wild populations (Vargas et al., 2009). The ILCBP lynx intended for reintroduction are subadults ( $8-20$ months). The Iberian lynx is a specialist predator whose circadian rhythm is synchronized with the activity of its main prey, the rabbit (Oryctolagus cuniculus; Delibes, 1980). Both rabbits and lynx are active primarily at night and during twilights (Beltrán, 1988; Jilge and Hudson, 2001).

The Iberian lynx is a semialtricial species whose young are born with poorly developed sensory and locomotor systems (Yerga et al., 2014). The pattern of circadian activity is not usually present in altricial species at birth (Ibuka, 1984, Kowalska et al., 2010). Rhythms typically appear days or weeks after birth, once the cubs leave the den and are exposed to local environmental factors such as the daylight cycle and temperature. Furthermore, mothers can act as synchronizers of the circadian behavioral rhythm of their young (Favreau et al., 2009).

The aim of this paper is to describe the ontogeny of the circadian activity rhythms in Iberian lynx born as part of the ILCBP from birth to subadult age and to verify if they develop a bimodal circadian pattern similar to the one they will need in the wild.

\section{Material and methods}

The activity of 61 Iberian lynx (36 males and 25 females) born in two specific breeding centers, "El Acebuche" (hereafter EA, 3703'00" N 6³3'17" W) and "La Olivilla" (hereafter LO, $\left.38^{\circ} 20^{\prime} 37^{\prime \prime N} 3^{\circ} 33^{\prime} 33^{\prime \prime} \mathrm{W}\right)$, both located in Andalusia, Spain, was studied. The cubs were born between 2008 and 2011 and derive from 28 litters from 13 different mothers. 
112 Housing conditions and protocols for handling animals were similar in the two breeding centers.

113 Each mother and its litter were housed in a big and enriched enclosure. The size of the

114 enclosures varied between the breeding centers (550 $\mathrm{m}^{2}$ in EA and $1000 \mathrm{~m}^{2}$ in LO). In both

115 breeding centers, the facilities included a main outdoor area enriched with the typical vegetation

116 of the Mediterranean habitat, sleeping structures, two or three dens, burrows where rabbits were

117 released (see below), and visual barriers that allowed the lynx to hide from the view of keepers.

118 The husbandry of the animals was planned so as to minimize disturbances to the animals and to

119 avoid imprinting on humans as far as possible. Sometimes cubs were abandoned by their

120 mothers and had to be hand-reared (13 cubs in the study). Those hand-reared cubs were kept in

121 an incubator room during the first month of life. Later these animals were transferred to the

122 enclosures and housed alone (i.e. without their mothers and brothers), where they were bottle

123 fed for one additional month. At two months of age the cubs were weaned, and from that age

124 onwards both mother-reared and hand-reared cubs were fed live wild rabbits. In order to

125 stimulate behaviors similar to those exhibited by lynxes in the wild, the animals were fed, as far

126 as possible, with wild rabbits released in the burrows throughout the day.

\subsection{Sampling method}

129 The activity of the cubs was recorded by a remote video surveillance system. It was considered

130 that an animal was active when it was awake. The enclosures had 2-3 mobile cameras and an

131 additional fixed camera in each den. All cameras were equipped with infrared lights that

132 allowed the monitoring of the cubs 24 hours a day. The video surveillance system was

133 continuously operated (24h) by trained observers from a room located 150 meters away from

134 the enclosures. Thus, it was possible to record activity throughout the day without disturbing the 135 lynxes.

136 The activity of the cubs was tracked between birth and 7 months of age using a point sampling

137 method. The interval of recordings was predefined. The activity of each cub was recorded every

13820 minutes in 2008 and 2009, and every 60 in 2010 and 2011, 24 hours a day, three to seven

139 days a week. In total, 139,897 activity records were obtained, and the activity of each cub was 
140 documented between 168-216 times per week. The potential bias due to the amount of activity

141 records obtained by lynx in a time interval was considered for the analysis of the activity.

142 In order to establish whether the amount of time that the captive young lynx remained active,

143 and the activity pattern were similar to that observed in nature, the activity of captive lynx was

144 compared with the activity of young and subadult lynx monitored in a long-term study on the

145 ecology of the Iberian lynx performed in the north of Donaña National Park between 1993 and

1461996 (Palomares et al., 2001), $15 \mathrm{~km}$ from the EA breeding center. In that study, 26 lynx were

147 caught and radio tracked an average of $274( \pm 60)$ days, of which 18 (10 females and 8 males)

148 were non-adult lynx. All lynx were fitted with 150-151 MHz radio-collars (Wildlife Materials,

149 Inc., Carbondale, Illinois) which contained tip switches to monitor activity. The activity of each

150 lynx was recorded an average of 10 times a week (range 1-59), including day and night

151 locations. In addition, 11 of these animals were followed in 20 intensive $24 \mathrm{~h}$ monitoring

152 sessions, where the animals were located and their activity recorded once per hour, beginning at

153 12:00 h of a given day and ending at 12:00 $\mathrm{h}$ of the next day (see details in Palomares et al.,

154 2001).

155

$156 \quad 2.2$ Statistical analysis

157 2.2.1 Daily activity

158 The daily activity (estimated as the proportion of daily records where the lynxes were active)

159 was calculated and the influence of age (in weeks), sex, rearing method (hand or mother-reared)

160 and breeding center (EA, LO) was evaluated through a generalized linear mixed model

161 (GLMM). This method is suitable for repeated measures data and provides estimates of the

162 parameters for each level of the random effects. Sex, rearing method, breeding center and age

163 were included as fixed factors and the individual lynx and the number of activity records

164 registered by lynx as random factors to account for the non-independence of the data from the

165 same animal and the variations in the number of records obtained by lynx in a time interval. A

166 model for each of the possible combinations of fixed effects was constructed. The set of

167 candidate models were ordered according to the AIC value. Analysis was performed using the 
169 performed to assess differences in the daily activity of the captive-born cubs and non-adult wild

170 lynx. Normality was tested before performing the analysis. In all cases, $\alpha$-value was 0.05 .

\subsubsection{Circadian rhythm}

173 The circadian activity rhythm of each lynx cub, estimated as the proportion of active records in

174 every hour in each month, was calculated. It was verified that the number of activity records

175 registered per animals did not alter the proportion of activity in this analysis (Mardia-Watson-

176 Wheeler test, $\mathrm{W}=5.0968, \mathrm{df}=2, \mathrm{p}=0.078$ ). The effect of age (in months), sex, breeding

177 center, rearing method and birthplace (captivity or wild) on the circadian rhythms of the cubs

178 was evaluated. Pairwise comparisons of the activity rhythms between sexes, breeding centers,

179 rearing methods and birthplace were performed by estimating the overlap coefficient $\Delta_{4}$, as

180 suggested by Ridout and Linkie (2009) for large sample sizes. This overlap coefficient, which

181 can have values between 0 (no overlap) and 1 (complete overlap), was obtained by taking the

182 minimum of activity of the two groups at each time of day. The accuracy in the estimation of $\Delta_{4}$

183 was obtained by calculating the standard deviation of 500 bootstrap samples.

184 However, the overlap coefficient is solely descriptive, and thus it does not provide a threshold

185 that can determine the existence of significant differences between the compared groups. Thus,

186 a Mardia-Watson-Wheeler test (MWW test; Batschelet, 1981) was performed to compare the

187 distribution of circadian activity. This test combines the activity data and orders them in

188 increasing angles, so that they are distributed interspersed around the daily cycle, and a uniform,

189 or circular rank, score is then calculated. If the distribution of samples is the same, the resulting

190 vector will be short and similar. Significant differences between the lengths of the vectors lead

191 to a high value of the statistic $\mathrm{W}$ and the rejection of the null hypothesis that the distributions

192 are equal (Kovach, 2011). All analyzes were performed using R (R Development Core Team,

193 2008) software, including the package 'circular' for the MWW test. 


\subsection{Daily activity}

197 During the first five weeks of age, while the cubs remain in the den, they were active around

$19830 \%$ of the day (Fig. 1). Afterwards, between the sixth and the ninth week of life, there was a

199 progressive increase in daily activity from $30 \%$ to $50 \%$. And finally, daily activity remained at

$20050 \%$ from the ninth week of age to the end of the study (at seven months old).A slight decrease

201 in the amount of activity occurred between weeks 21 and 25 (during the summer, Fig. 1).

202 The model that best explained (i.e. had the lowest AICc) the daily activity of the Iberian lynx

203 cubs included age and breeding center as explanatory variables (Table 1). The daily activity of

204 lynxes changed significantly with the age $(\mathrm{z}=10.926, \mathrm{p}<0.01)$, and it was different for each

205 breeding center $(\mathrm{z}=5.663, \mathrm{p}<0.01)$. Cubs born in LO displayed less activity than those born in

206 EA $(5 \% \pm 1$; mean \pm SE). No significant differences between mother-reared and hand-reared

207 cubs were found $(z=1.353, p=0.202)$, nor between males and females $(z=0.594, p=0.745)$.

208 Daily activity of wild lynx was $45 \pm 5 \%$. Only the daily activity of cubs over 9 weeks was used

209 to assess differences with the daily activity of wild animals. No significant differences were

210 found comparing the daily activity of captive and wild lynx (ANOVA, $F=0.94, p=0.336$ ).

211

212

\subsection{Circadian rhythm}

213 The evolution of the circadian pattern of lynx cubs born in captivity is summarized in Fig. 2.

214 During the first month of life, the activity of cubs was quite uniform throughout the 24 hour

215 day, varying between $19 \pm 3.2 \%$ at $20: 00 \mathrm{~h}$ and $39 \pm 6.2 \%$ at $12: 00 \mathrm{~h}$. In the second month of life,

216 a bimodal pattern emerged. This coincided with the first time the cubs left the den (at $33 \pm 0.3$

217 days old, mean \pm SE). Activity increased at both dawn and dusk with peaks at 6:00h $(58 \pm$

$2182.4 \%)$ and 19:00h $(73 \pm 2.9 \%)$. In the evening, the activity peak was shorter and higher than at

219 dawn, when activity lasted longer but never surpassed 60\%. From the third to the seventh month

220 of life, the bimodal activity pattern was fully established. The maximum activity peak at dawn

221 and at dusk exceeded $80 \%(83 \pm 2.2 \%$ between $4: 00 \mathrm{~h}$ and 5:00h and $85 \pm 1.5 \%$ between 18:00h

222 and 19:00h, respectively) and activity at midday was reduced (below $22 \%$ from 12:00h to

223 14:00h). 
224 Males and females lynxes exhibited a similar circadian rhythm pattern (fig. 3a), with a $\Delta_{4}$ 225 overlap coefficient of $0.96 \pm 0.006$. The MWW test showed no significant differences in the 226 distribution of activity between sexes throughout the day $(\mathrm{W}=1.93, \mathrm{p}=0.381)$. On the other 227 hand, there were significant differences in the activity circadian pattern depending on the rearing method (MWW test; $\mathrm{W}=43.73, \mathrm{p}<0.01)$ and the breeding center $(\mathrm{MWW}$ test; $\mathrm{W}=$ 10.92, $\mathrm{p}<0.01)$, although both $\Delta_{4}$ overlap coefficients were high $(0.88 \pm 0.016 ; 0.90 \pm 0.015$,

230 respectively). At night, hand-reared cubs exhibited less activity than those reared by mothers. At

231 dawn, the latter developed their maximum activity at 4:00h, while hand-reared cubs had their

232 maximum at 6:00h. During midday, the activity of mother-reared cubs decreased quickly and

233 stayed below the activity of hand-reared cubs until the dusk peak of activity, in which the 234 groups displayed a similar level of activity (fig. 3b). The activity of the cubs born in LO was 235 less than that of EA cubs for much of the day (from 9:00h to 24:00h; fig. 3c).

236 Only the activity pattern of mother-reared cubs was compared with the circadian rhythm of non-

237 adult wild lynxes (Fig. 3d), because hand-reared cubs were not intended for reintroduction.

238 Wild animals were more active at night than captive animals (around 60\% between 21:00h and

239 1:00h). After that, the activity of the wild lynxes decreased, until it increased again just before

240 the dawn. This peak reached $53 \%$ of activity at 6:00h, being much lower than the maximum

241 observed in captive animals. During midday activity remained low in both groups (about 20\%).

242 During the dusk, captive animals began to increase their activity earlier than wild animals and

243 they reached a higher maximum value. However, the peak of activity was also observable in

244 wild animals. The maximum was reached at $20: 00 \mathrm{~h}$ with $75 \%$ of activity. The $\Delta 4$ overlap

245 coefficient was $0.85 \pm 0.016$, but the difference was significant (MWW test, $\mathrm{W}=30.09$,

$246 \mathrm{p}<0.01)$

248 4. Discussion

$249 \quad 4.1$ Daily activity

250 Daily activity of captive-born Iberian lynx cubs varied during their development. Changes in

251 Iberian lynx activity occurred in a similar manner to that observed in the domestic cat 
252 (Hoppenbrouwers and Sterman, 1975), although cats develop slightly faster. This variation was

253 closely related to the sensory and locomotor development of cubs and with their ability to

254 interact with their environment. During the first month of life, while the cubs remained in the

255 den, they were active $30 \%$ of the day. During this time, the sensory and locomotor development

256 of lynx cubs was low (Yerga et al., 2014), so their ability to respond to external stimuli was

257 diminished. During this first month of life, nursing was the only activity that cubs displayed, as

258 they remained asleep the rest of the day.

259 A second period in the ontogeny of the activity of the lynx, between the six and the eight weeks

260 of age, can be described. The beginning of this period coincided with the first explorations

261 outside the den. At this age the cubs had reached a weight of $1 \mathrm{~kg}$ and were able to walk, and the

262 senses of sight and hearing were fully developed (Yerga et al., 2014). Cubs began to exhibit

263 new behaviors, like playing and exploring. The time that they spent engaging in these new

264 behaviors led to an increase in activity from $30 \%$ to $50 \%$. A third period in the ontogeny of the

265 activity of the Iberian lynx cubs began at 9 weeks of age. Cubs honed their motor skills, spent

266 more time playing and exploring the environment, lactation ended and they learned to hunt. The

267 activity of the cubs then remained around 50\% for a number of weeks. The slight decrease of

268 activity observed between weeks 21 and 25 , which correspond to the warmest period of the

269 summer, was probably due to an increase in temperature that typically leads to a decrease in the

270 activity of lynxes (Beltrán and Delibes, 1994; McNab, 1970).

271 Even though hand-reared cubs were raised in a very different environment during the first

272 month of life and they were subsequently housed alone, their level of activity was similar to that

273 of cubs reared with their mother and siblings. We did not study whether there are specific

274 differences during development or in the type of behaviors they performed by the cubs when

275 they are active, but from the second month of life, we would expect hand-reared and mother-

276 reared cubs to show a different ethogram, as the former cannot perform some behaviors (e.g.

277 social interactions). It would be necessary to study more thoroughly the behavior of both groups

278 to assess how hand-reared cubs modify their time budget. 
The effect of sex on daily activity has been studied in adult mammals, but not in cubs. It seems

280 that differences in daily activity between sexes are related to variations throughout the year that

281 depend largely on differences in behavior between breeding and non-breeding seasons (Schmidt

282 et al., 2009). Therefore, it is expected that this effect does not occur in animals thathave not

283 reached sexual maturity. In the Iberian lynx, adult males are slightly more active than females,

284 both in captivity (Penabad et al., 2012) and in the wild (Beltrán, 1988), but the differences are

285 not significant. The animals in our study were juveniles, in which sex-specific behaviors are still

286 not observed, thus consistent with the absence of differences in daily activity.

287 The differences in daily activity between the breeding centers are probably related to the climate

288 of each site. Cubs reared in LO spent less time active than those born in EA as the average daily

289 and maximum temperatures are higher in LO during summer (García, 2011).

290 Oftentimes, captive felids are generally less active than their wild conspecifics, which is

291 probably due to the fact that the lack of stimuli in the enclosures does not allow them to carry

292 out all of the typical behaviors of the species (Weller and Bennett, 2001). However, the activity

293 of captive Iberian lynxes, once it was stabilized after 9 weeks, was similar to that observed in

294 the free-ranging Iberian lynxes. Anyway, a further study would be necessary to know if the type

295 of behavior they perform when they are active are similar in both groups.

\section{$297 \quad 4.2$ Circadian rhythm}

298 The development phases of the circadian pattern in the captive-born Iberian lynx cubs coincided

299 with the development of the amount of daily activity. The lack of a defined pattern of activity in

300 newborns has been widely observed in other altricial species (Ibuka, 1984). The appearance of

301 overt rhythms depends on the developmental stage (Vargas \& Anderson, 1998; Weinert, 2005).

302 Iberian lynx cubs had not developed their sensory and locomotor systems and the main

303 zeitgebers, namely light and temperature, did not have any influence inside the dens. In

304 addition, mothers nursed the cubs regularly for 24 hours a day, so that the activity of the cubs

305 was almost constant throughout the day. Once the cubs were out of the den, they were subjected 
to the environmental factors that regulate the circadian cycle and they gradually established the

307 characteristic bimodal pattern of the species.

308 The overlap of circadian rhythms obtained in pairwise comparisons by sex, rearing method and

309 breeding center were very high and the bimodal pattern of circadian activity was maintained in

310 all groups. However, some significant differences were observed. The peak of maximum

311 activity at dawn occurred two hours later in hand-reared cubs than in mother-reared ones. This

312 may be due to the fact that the hand-reared cubs had imprinted on humans. During the morning,

313 keepers performed the tasks of cleaning and maintenance in the area where the enclosures were

314 located. Their presence was a positive stimulus for these cubs, so hand-reared cubs spent more

315 time active trying to interact with the keepers. On the other hand, mother-raised cubs had little

316 contact with keepers during development, so humans were a negative or at least neutral

317 stimulus, and during the morning these cubs were resting. As occurred with daily activity, the

318 effect of the breeding center is likely to be related to the higher temperatures recorded at LO

319 (García, 2011), which resulted in the lower activity, from midday until night, of cubs born at

320 this center.

321 The comparison of activity patterns between wild and captive lynxes has some limitations. The way the data was recorded for the two groups is markedly different, the records were made in different years with different weather conditions, and also the wild lynxes had to adapt their activity to a changing and less predictable environment, especially concerning the availability of

325 food. Wild lynxes were more active at night, as are rabbits (Monterroso et al., 2013), their

326 preferred prey. Despite all this, there was a bimodal pattern in wild and captive lynxes, both

327 exhibiting peaks of activity at dawn and at dusk. This is consistent with numerous studies which

328 have shown that the circadian rhythm is regulated by an endogenous component (Aschoff,

329 1960; Minors and Waterhouse, 1984), apart from environmental factors.

\section{5. Conclusions}

332 Many studies have found that captive animals often develop a modified circadian cycle and

333 exhibit less activity than those who live in the wild (Berger, 2011; Weller and Bennett, 2001). 
334 However, our results showed that, once the lynx cubs had completed their development, the

335 time they remained active and the daily distribution of this activity over a24 hour period was

336 similar to that observed in free-living adults. This is probably related to the type of husbandry

337 and the size and level of enrichment of the enclosures. The husbandry of the animals was

338 minimized to reduce the influence of human presence on their behavior. The enclosures far

339 exceeded the minimum size recommended by the Association of Zoos and Aquariums (AZA),

340 which is $8 \mathrm{~m}^{2}$ for small felids between 10 and $20 \mathrm{~kg}$ (Mellen, 1997). Furthermore, it has been

341 shown that the degree of enrichment is closely related to the prospect of developing a wide

342 variety of natural behaviors and therefore increases the activity and welfare of animals in

343 captivity (Bashaw et al., 2003; Young, 2003). The ILCBP enclosures included a wide variety of

344 vegetation, vertical structures, visual barriers and burrows where prey could hide, and as a result

345 hunting was more difficult and the lynxes had to perform various behaviors, such as stalking.

346 These actions appear to be essential to ensure that the captive-born Iberian lynxes at the ILCBP

347 are suitable, from the point of view of circadian activity rhythms, to contribute to the

348 reintroduction projects of the species in the wild.

350 Acknowledgments

351

352 Special thanks to the staff of "El Acebuche" and "La Olivilla" breeding centers (veterinarians,

353 keepers, video-surveillances and voluntaries). Funding for this work was provided by

354 Organismo Autónomo de Parques Nacionales (MAGRAMA), Junta de Andalucía, DGICYT

355 and DGES (projects PB90-1018, PB94-0480 and PB97-1163) and a FPU-grant from MEC (ref:

356 AP2008-01148).

357

358 References

359 Albrecht, U., Eichele, G., 2003. The mammalian circadian clock. Curr. Opin. Genet. Dev., 13, $360 \quad 271-277$. 
Aschoff, J., 1960. Exogenous and endogenous components in circadian rhythms, in: Cold

362 Spring Harbor Symposia on Quantitative Biology: Volume XXV. Biological Clocks. Cold

363 Spring Harbor Press, New York, pp. 11-28.

364 Aton, S.J, Block, G.D., Tei, H., Yamazaki, S., Herzog, E.D., 2004. Plasticity of circadian

365 behavior and the suprachiasmatic nucleus following exposure to non-24-hout light cycles. J.

366 Bio. Rhythms., 19, 198-207.

367 Bashaw, M.J., Bloomsmith, M.A., Marr, M.J., Maple, T.L, 2003. To hunt or not to hunt? A

368 feeding enrichment experiment with captive large felids. Zoo Biol., 22, 189-198.

369 Batschelet, E., 1981. Circular statistics in biology. Academic Press, London.

370 Beltrán, J.F., 1988. Behavioral ecology of Iberian lynx (Lynx pardina Temminck, 1824) in

371 Doñana National Park, SW. Spain. Ph.D. Thesis. University of Sevilla. Spain.

372 Beltrán, J.F., Delibes, M., 1994. Environmental determinants of circadian activity of free-

373 ranging Iberian lynxes. J. Mammal. 75, 382-393.

374 Berger, A., 2011. Activity patterns, chronobiology and the assessment of stress and welfare in

375 zoo and wild animals. Int. Zoo Yb., 45, 80-90.

376 Borbély, A.A., Neuhaus, H.U., 1978. Circadian rhythm of sleep and motor activity in the rat

377 during skeleton photoperiod, continuous darkness and continuous light. J. Comp. Physiol., 133,

$378 \quad 71-87$.

379 Carlstead, K., 1996. Effect of captivity on the behavior of wild mammals, in: Kleiman, D.,

380 Allen, M.E., Thompson, K.V., Lumpkin, S., (Eds.).Wild mammals in captivity: principles and

381 techniques. University of Chicago Press, Chicago, pp. 317-333.

382 Clubb, R., Vickery, S.S., 2006. Locomotory stereotypies in carnivores: does pacing stem from

383 hunting, ranging, or frustrated escape?, in: Mason, G., Rushen, J., (Eds.). Stereotypic Animal

384 Behaviour: Fundamentals and Applications to Welfare. end.edn. CAB International,

385 Wallingford, UK, p. 58-85.

386 Daan, S., Aschoff, J., 1975. Circadian rhythms of locomotor activity in captive birds and

387 mammals: variations with season and latitude. Oecol., 18, 269-316. 
Delibes, M., 1980. Feeding ecology of the Spanish lynx in the Coto Doñana. Acta Theriol., 25, 309-324.

390 Eriksen A., Wabakken, P., Zimmermann, B., Andreassen, H.P., Arnemo, J.M., Gundersen, H.,

391 Liberg, O., Linnell, J., Milner, J.M., Pedersen, H.C., Sand, H., Solberg, E.J., Storaas, T., 2011.

392 Activity patterns of predator and prey: a simultaneous study of GPS-collared wolves and moose.

393 Anim. Behav., 81, 423-431.

394 Favreau, A., Richard-Yris, M.A., Bertin, A., Houdelier, C., Lumineau, S., 2009. Social

395 influences on circadian behavioural rhythms in vertebrates. Anim. Behav, 77, 983-989.

396 García, M. A.(Ed.), 2011. Atlas climático ibérico. Temperatura del aire y precipitación (1971-

397 2000). AEMET/IMP.

398 Halle, S., 2000. Ecological relevance of daily activity patterns, in: Halle, S., Stenseth, N.C.,

399 (Eds.). Ecological studies: Activity patterns in small mammals, an ecological approach.

400 Springer, New York, pp. 67-90.

401 Hoppenbrouwers, T., Sterman, M.B. Development of sleep state patterns in the kitten. Exp.

402 Neurol., 49, 822-838.

403 Ibuka, N., 1984. Ontogenesis of circadian sleep-wakefulness rhythms and developmental

404 changes of sleep in the altricial rat and in the precocial guinea pig. Behav. Brain. Res., 11, 185-

405196.

406 Jilge, B., Hudson, R., 2001. Diversity and development of circadian rhythms in the European

407 rabbit. Chronobiol. Int., 18, 1-26.

408 Kavanau, J.L., Ramos, J., 1975. Influences of light on activity and phasing of carnivores. Am.

409 Nat., 109, 391-418.

410 Kolbe, J. A., Squires, J. R., 2007. Circadian activity patterns of Canada lynx in Western

411 Montana. J. Wildl. Manage., 71, 1607-1611.

412 Kovach, W.L., 2011. Oriana-circular statistics for Windows. Kovach Computing Services,

413 Pentraeth.

414 Kowalska, E., Moriggi, E., Bauer, C., Dibner, C., Brown, S. A., 2010. The circadian clock starts

415 ticking at a developmentally early stage. J. Biol. Rhythms, 25, 442-449. 
416 Lima, S.L., 2002. Putting predators back into behavioral predator-prey interactions. Trends

417 Ecol. Evol, 17, 70-75.

418 Manteca, X., 2009. Behavioral problems of wild felids in captivity, in: Vargas, A.,

419 Breitenmoser, C., Breitenmoser, U. (Eds.), Iberian Lynx Ex Situ Conservation: An

420 Interdisciplinary Approach. Fundación Biodiversidad, Madrid, Spain, pp. 126-135.

421 McNab, B.K., 1970. Body weight and the energetics of temperature regulation. J. Exp. Biol., 53, $422 \quad 329-348$.

423 Mellen, J.D., 1997. Minimum husbandry guidelines for mammals: small felids. American 424 Association of Zoos and Aquariums.

425 Minors, D.S., Waterhouse, J.M., 1984. The sleep-wakefulness rhythm, exogenous and

426 endogenous factors (in man). Experientia, 40, 410-416.

427 Monterroso, P., Alves, P. C., Ferreras, P., 2013. Catch me if you can: diel activity patterns of 428 mammalian prey and predators. Ethol, 119, 1044-1056.

429 Munson, L., Terio, K. A., Worley, M., Jago, M., Bagot-Smith, A., Marker, L., 2005. Extrinsic

430 factors significantly affect patterns of disease in free-ranging and captive cheetah (Acinonyx

431 jubatus) populations. J. Wildl. Dis., 41, 542-548.

432 Palkova, M., Sigmund, L, Erkert, H.G., 1999. Effect of ambient temperature on the circadian

433 activity rhythm in common marmosets, Calithrix j. jacchus (primates). Chronobiol. Int., 16, $434 \quad 149-161$.

435 Palomares, F., Delibes, M., Revilla, E., Calzada, J., Fedriani, J.M., 2001. Spatial ecology of the 436 Iberian lynx and abundance of European rabbit in southwestern Spain. Wildl. Monogr., 148, 143736.

438 Penabad, L., Rivas, A., Calzada, J., 2012. Ritmos de actividad del lince ibérico (Lynx pardinus) 439 en cautividad. Galemys, 24, 57-63.

440 Pittendrigh, C.S., 1993. Temporal organization - Reflections of a Darwinian clock-watcher.

441 Annu. Rev. Physiol, 55, 17-54.

442 Ridout, M.S., Linkie, M., 2009. Estimating overlap of daily activity patterns from camera trap 443 data. J. Agric. Biol. Environ. Stat., 14, 322-337. 
444 Schmidt, K., Nakanishi, N., 2009. The reproductive tactics and activity patterns of solitary

445 carnivores: the Iriomote cat. J. Ethol., 27, 165-174.

446 Shepherdson, D. J., Carlstead, K., Mellen, J. D., Seidensticker, J., 1993. The influence of food

447 presentation on the behavior of small cats in confined environments. Zoo Biol., 12, 203-216.

448 Vargas, A., Anderson, S.H., 1998. Black-footed ferret (Mustela nigripes) behavioral

449 development: aboveground activity and juvenile play. J. Ethol., 16, 29-41.5

450 Vargas, A., Sánchez, I., Martínez, F., 2009. Interdisciplinary methods in the Iberian lynx (Lynx

451 pardinus) Conservation Breeding Programme, in: Vargas, A., Breitenmoser, C., Breitenmoser,

452 U., (Eds.). Iberian lynx Ex-Situ Conservation: an interdisciplinary approach. Fundación

453 Biodiversidad, Madrid, pp. 56-71.

454 Weinert, D., 2005. Ontogenetic development of the mammalian circadian system. Chronobiol.

455 Int., 22, 179-205.

456 Weller, S.H., Bennett, C.L., 2001.Twenty-four hour activity budgets and patterns of behavior in

457 captive ocelots (Leopardus pardalis). Appl. Anim. Behav. Sci., 71, 67-79.

458 Young, R. J., 2003. Environmental enrichment or captive animals. Wiley-Blackwell, Oxford.

459 Yerga, J., Calzada, J., Manteca, X., Vargas, A., Rivas, A., 2014. Early development and growth

460 in captive-born Iberian lynx (Lynx pardinus). Zoo Biol. DOI: 10.1002/zoo.21148

461

462

463

464

465

466

467

468

469

470 


\begin{tabular}{c|ccccc} 
Model & df & logLik & AICc & $\Delta$ AICc & W \\
\hline A + BrC & 6 & 2968.80 & -5925.59 & 0,00 & 0.96 \\
A + BrC + ReM & 7 & 2966.28 & -5918.54 & 7.05 & 0.03 \\
A + BrC $+\mathrm{S}$ & 7 & 2965.38 & -5916.73 & 8.86 & 0.01 \\
Null model & 4 & 2911.10 & -5814.20 & 111.39 & 0.00 \\
\hline
\end{tabular}

472

473 Table 1. Comparison of the different models for describing the ontogeny of the daily activity of 474 Iberian lynx cubs. A is the age, $\mathrm{BrC}$ is the breeding centre, $\mathrm{ReM}$ is the rearing method and $\mathrm{S}$ is 475 the sex. Degrees of freedom (df), log-likelihood (logLik), AICc (corrected Akaike's Information 476 Criterion), $\triangle \mathrm{AICc}$ (difference between the AICc of a model and the lowest value of AICc for 477 the set of models) and Akaike weight (W) for each model is provided. The table includes those 478 models in which $\triangle \mathrm{AICc}<10$ and the null model.

479

480 481

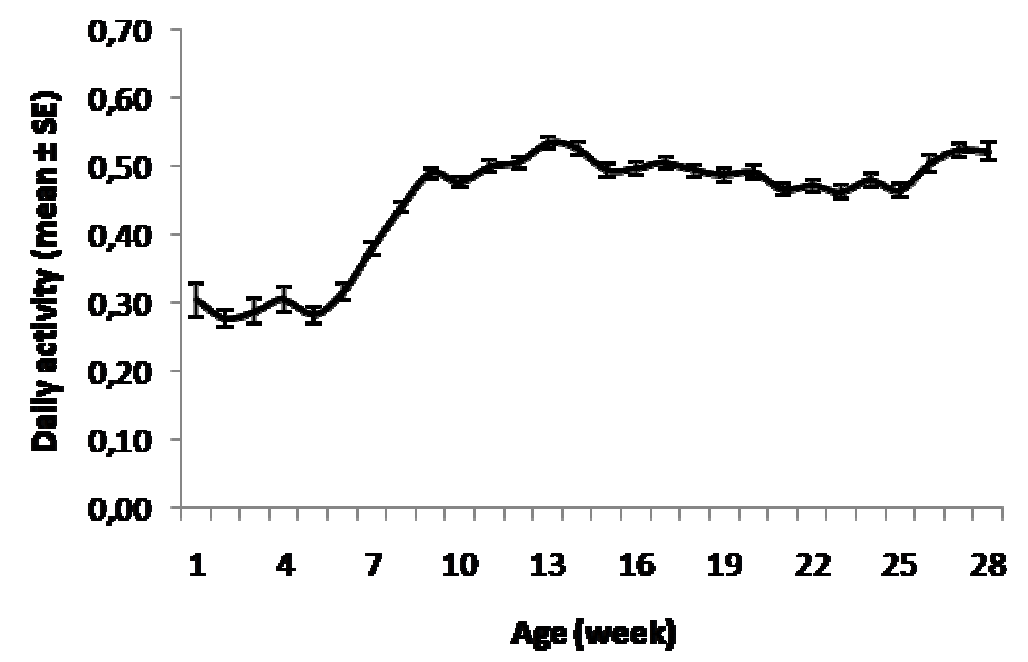

482

483 Figure 1. Daily activity (proportion of daily records where the lynxes were active, mean \pm SE)

484 of the Iberian lynx cubs born in captivity between birth and seven months old. 


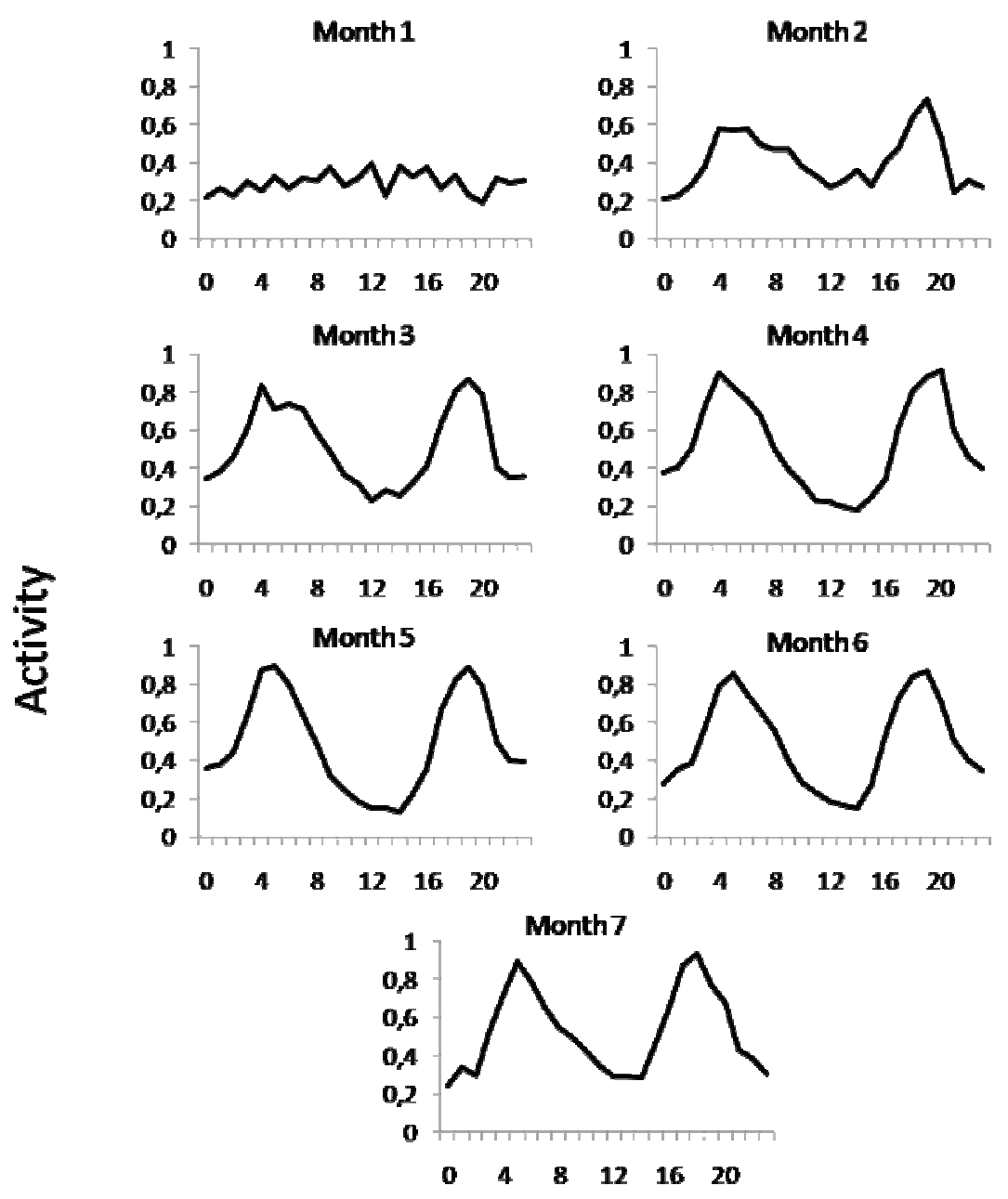

487

Hour

488

489

490 Figure 2. Circadian activity pattern of Iberian lynx cubs born in captivity during the first seven

491 months of life. Activity is presented as the proportion of records cubs were active for each

492 hourly interval.

493

494 

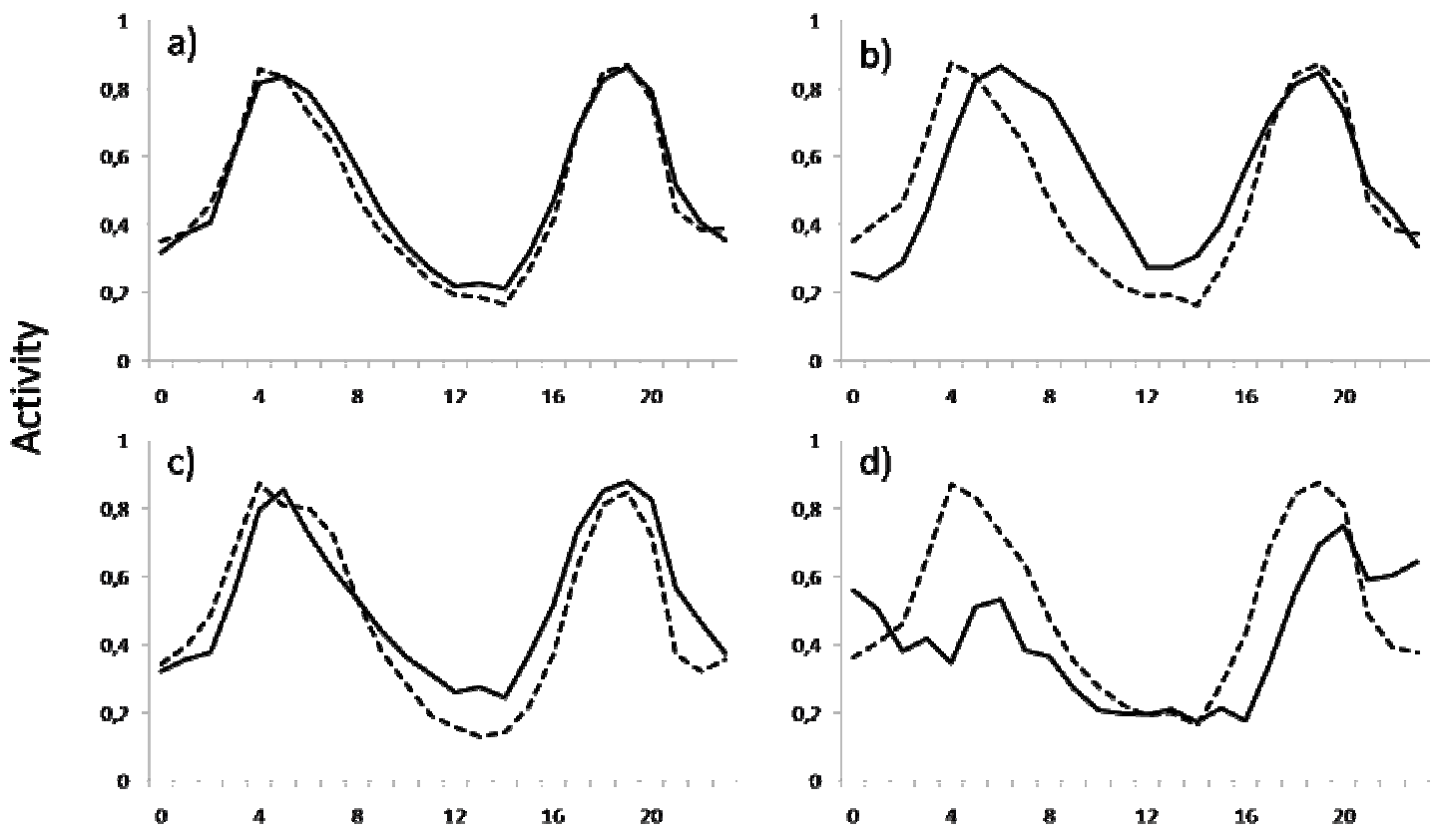

\section{Hour}

496 Figure 3. Pairwise comparison of circadian activity rhythms. Activity is presented as the ratio

497 of time that the animals were active: a) males (solid line) vs females (dashed line), b) hand-

498 reared (solid line) vs. mother-reared (dashed line), c) EA (solid line) vs LO (dashed line), d)

499 wild (solid line) vs captive (dashed line). 